\title{
Behavior analytic based virtual reality interventions to teach adaptive and functional skills for individuals diagnosed with autism: A systematic review
}

\author{
Amarie Carnett ( $\nabla$ amarie.carnett@vuw.ac.nz ) \\ Victoria University of Wellington https://orcid.org/0000-0003-0664-1346 \\ Leslie Neely \\ University of Texas at San Antonio https://orcid.org/0000-0002-2171-3304 \\ Siobhan Gardiner \\ Victoria University of Wellington \\ Marie Kirpatrick \\ University of Texas at San Antoni https://orcid.org/0000-0002-6253-0504 \\ John Quarles \\ University of Texas at San Antonio https://orcid.org/0000-0002-4790-167X \\ Kameron Christopher \\ 5National Institute of Water and Atmosphere
}

\section{Systematic Review}

Keywords: virtual reality, technology, behavior analysis, systematic review, quality review

Posted Date: January 13th, 2022

DOI: https://doi.org/10.21203/rs.3.rs-1255943/v1

License: @ (i) This work is licensed under a Creative Commons Attribution 4.0 International License. Read Full License 


\section{Abstract}

Virtual reality technologies hold promise for the therapy based on the science of applied behavior analysis as they can replicate real life environments and allow the user to role-play in a simulated environments. This literature review synthesizes the research base evaluating the effects of behavior analytic interventions delivered via virtual reality (VR) technology to teach adaptive and functional skills for individuals with autism.

Method: We conducted a systematic search in four databases followed by a reference search for those articles by the systematic database search. We also conducted a quality review using the Evaluative Method for Evaluating and Determining Evidence-Based Practices in Autism (Reichow, 2008).

Results: We identified 24 studies with a majority of the studies ( $n=18 ; 75 \%)$ utilizing group experimental or quasiexperiment research design, and the remaining $(n=6 ; 25 \%)$ utilizing single-case research design. Of those studies, ten targeted vocational related skills, seven targeted functional behaviors (e.g., problem behavior treatment, hypersensitivity, phobias), four targeted safety skills (e.g., driving, airplane travel, pedestrian safety), two studies targeted general functional skills, and one targeted exercise engagement. Of the 24 studies, 12 met the quality criteria to be classified as "strong" or "adequate" and can offer evidence on the integration of VR technology into the practice of behavior analysis for teaching adaptive or functional skills.

Discussion: Taken as a whole, the three studies (Cox et al., 2017; Hu \& Han, 2019; Wade et al., 2013) identified as "strong" quality studies were conducted by three different research teams, at three different locations, with 74 different participants and meet the qualifications to be considered a promising practice.

\section{Introduction}

Recent numbers from the Centers for Disease Control and Prevention (CDC) indicate that 1 in 44 children have autism spectrum disorder (ASD; Maenner et al., 2021). ASD is characterized by a range of strengths (e.g., attention to detail) and needs (e.g., social communication skills). The needs of those with ASD can best be supported through interventions, particularly those considered to be evidence-based practices. Evidence-based practices are interventions and teaching methods that are substantially supported through research to produce positive outcomes (Hume et al., 2021). One evidence-based practice aimed at improving socially valid behavioral concerns is applied behavior analysis (ABA). ABA is a branch of the science of behavior analysis which relies on assessment to inform individualized interventions designed to reduce or strengthen human behavior (Cooper et al., 2020). There is a strong body of evidence to demonstrate its use in supporting individuals with ASD (Leaf et al., 2020; Tiura et al., 2017). Evidence-based practices for individuals with ASD that are aligned with the principles of $A B A$ include discrete trial training, functional communication training, prompting, and self-monitoring, to name a few (Hume et al., 2021). However, as our society shifts to a more technological world, there has been an increase in the use of technology-based interventions to support individuals with ASD (Thai \& Roberts-Nathan, 2018).

Technology-aided instruction and intervention (TAll) is an evidence-based practice for individuals with ASD in which technology is the primary component of the intervention (Hume et al., 2021). This can include the use of more common technology, such as the use of computers or mobile device application, as well as more advanced technology, like virtual reality (VR) and augmented reality (AR), or robots. For example, in Rosenbloom et al. (2016), researchers investigated the effectiveness of using a commercially developed mobile device application, IConnect (Wills \& Mason, 2014), for self-monitoring in the general education classroom. The results of the study 
indicated strong outcomes for increasing on-task behavior and reducing disruptive behaviors, including good social validity from the participant and the teacher. In McMahon et al. (2015), the authors compared the use of Google Maps, a traditional map, and AR to teach navigation to unknown employment settings to post-secondary students with disabilities. Results of this study indicated that students were more successful (i.e., independent) when using AR. TAll has demonstrated to be effective at supporting a variety of needs (e.g., communication, academics, adaptive skills, etc.) for individuals with ASD from infancy to adulthood (Hume et al., 2021). Advanced technology, like VR, has become more accessible over the last decade, thus, increasing its popularity within our society.

VR is a three-dimensional, computer-generated visual experience that can replicate real life that the user can interact with (Clay et al., 2021; Lorenzo et al., 2016). It allows for different types of immersive experiences for the user: non-immersive (e.g., desktop display), semi-immersive (e.g., smart glasses), and immersive (e.g., headmounted display; Di Natale et al., 2020). There are several advantages to the use of VR interventions for individuals with ASD, which align with the principles and dimensions of ABA. A clear benefit is its ability to emulate a real-world setting and offer experiences that cannot otherwise be captured through typical teaching methods like text (i.e., written instructions) or videos (Bailenson et al., 2008). VR allows for repeated practice of skills that may be difficult, or dangerous, to do in real life (e.g., safety skills; Karami et al., 2021). This is extremely advantageous for individuals with ASD as it may reduce the stress associated with learning adaptive and functional skills through more traditional means (Didehbani et al., 2016). It allows for individualization as the implementer can adapt the user's experience (e.g., appearance of the VR environment displayed, complexity of the task) to meet their specific needs (Bailenson et al., 2018). Reinforcement is given through real-time feedback and repetition, therefore, enhancing the learning quality (Clay et al., 2021; Kamari et al., 2021). Because VR can mimic the real-world, it promotes generalization. While this could be achieved using in-vivo teaching methods, it enables possibilities beyond face-to-face teaching. VR uniquely enables the tracking of a user's movements (Bailenson et al., 2008), which provides valuable information as to where the user responds, interprets, and interacts with the world (Lorenzo et al., 2018). Additionally, individuals with ASD have shown a strong preference for technology (Valencia et al., 2019), thus, increasing the social validity of this type of intervention.

Despite an increase in research regarding VR and ASD, there are a limited number of systemic literature reviews to further inform research and practice. A couple of reviews focus on technology-based interventions, which do include information regarding VR (e.g., Barton et al., 2017). However, these reviews may not have captured the extant literature on VR given this was not the focus; therefore, search terms encapsulating VR may not have been used. There are two existing reviews that are specific to use of VR as an intervention for people with ASD. Both Mesa-Gresa et al. (2018) and Lorenzo et al. (2019) provided understanding of this topic, with the focus of Lorenzo et al. (2019) being focused specifically on immersive VR. Together, these reviews analyzed 43 published articles from 1990-2018. While these reviews give researchers and practitioners an understanding of how VR has been used, neither of them assessed the rigor of the research using quality indicators (e.g., What Works Clearinghouse). This is an important consideration as synthesizing the literature and evaluating the effectiveness of interventions without consideration for the quality of the research (e.g., threats to internal validity) will not be helpful in informing practice (Kratchowill et al., 2013).

Often practitioners rely on systematic reviews to give them insight on a specific intervention or target behavior that is socially significant to a client or student they are working with. Therefore, more focused reviews may provide an easier way for them to access the research. Currently, to the authors' best knowledge, four focused 
reviews exist on VR for people with ASD. Three of these four reviews focus on social communication skills (Irish, 2013; Parsons \& Mitchell, 2002; Vasquez et al., 2015) and one review focuses on the use of naturalistic interventions within the context of VR (Dechsling et al., 2021). A focus in these areas is not surprising given the diagnostic criteria for ASD relates to deficits in communication; however, individuals with ASD often have difficulty acquiring other skills as well. Additionally, neither of these reviews assessed the methodological rigor of the studies; therefore, it is unclear about the extent of the reliability of interpreting the outcomes of the included studies within their review. While there is a need to address the deficits of communication for those with ASD, it is also imperative to teach adaptive and functional skills in order to promote independence.

There is significant potential for VR to enable people with ASD to have meaningful opportunities to learn and generalize skills to their everyday life. The current review aims to (1) evaluate the current existing body of literature utilizing behavioral analytic interventions delivered using VR to target adaptive and functional skills for individuals with ASD, and (2) assess the methodological rigor of the literature to inform future research and practice for the use of VR when targeting adaptive and functional skills.

\section{Method}

\section{Search Procedures}

The researchers completed a systematic search of the following databases: PsychINFO, Medline, Psychology and Behavioral Sciences Collection, and ERIC. These searchers were conducted by combining a term to describe ASD (i.e., "Autis*," "Developmental disab*," "Asperger," "ASD") with a term to describe VR ("virtual reality") and ("intervention", "treatment"). The original search was conducted in September 2021 and yielded 191 articles after the removal of duplicates (see Figure 1 graphic results). Following the database searches, the third author did an initial screening of each article by their title and abstract and excluded articles that did not include the use of VR and ASD $(n=129)$. An additional search using Google Scholar was conducted to identify any additional articles. After excluding duplicates, a total of 34 articles were added to the total article list for application of the inclusion criteria. In total 67 articles were screened by their full text using the following inclusion and exclusion criteria and 50 were excluded with a total of 17 articles meeting inclusion criteria.

Next, an ancestral and forward search of the included articles was conducted. For the ancestral search, the references of the included articles were reviewed and extracted if titles contained any of the key search terms (provided above). For the forward search, Google Scholar was used to search the record of included articles by selecting the "cited by" button. Relevant articles citing the included article were reviewed for possible inclusion. All relevant articles were extracted from the ancestral and citation search into a Microsoft Excel ${ }^{\mathrm{TM}}$ spreadsheet. These articles then underwent the full inclusion review. The researchers conducted this iterative process and retrieved a total of 7 additional articles from the ancestral and forward search. The final number of articles included totaled 24 studies.

\section{Inclusion and Exclusion Criteria}

To be included in this review, articles had to meet the following criteria: (a) be peer-reviewed and published in English, (b) include at least one participant with an ASD, (c) implement a therapeutic intervention designed to establish/increase appropriate behavior or decrease interfering behaviors, (d) utilize an experimental design to evaluate the effects of the intervention on the target behaviors, (e) use a form of AR to facilitated the therapeutic 
intervention, and (f) provide quantitative data pertaining to the participant's acquisition of adaptive and functional target behaviors (e.g., teaching air travel behavior, treatment of phobia, learning pedestrian safety skills). Studies that did not collect data on an adaptive or functional target behavior or did not include a therapeutic intervention as the independent variable were excluded (e.g., social skills, communication skills). For example, Fitzgerald et al. (2018) conducted a study that evaluated the use of VR and video modeling to teach paper folding tasks (e.g., making a paper boat). However, this paper was excluded since although folding paper might have some functional and adaptive contexts, such as folding paper menus in the context of job skills, this was in the context of what could be viewed as an arts and craft activity, without a direct functional or adaptive context during the intervention. Additionally, the researchers included any study utilizing a quasi-experimental, group comparison experimental, or single-case experimental design. Studies evaluating the validity of AR interventions or participants' perspectives on using the technology were excluded. For example, McCleery et al. (2020) evaluated the usability and feasibility of an immersive VR program to teach police interaction skills for participants with autism but did not measure targeted skills gained from the intervention program, and thus was excluded from this review. Finally, any study that discussed the development of technologies or the architecture of the technologies but did not provide quantitative data on the effects of the intervention on the target dependent variables was excluded. For example, Trepagnier et al. (2005) discussed multiple computer-based and virtual environment technologies that are in development but did not utilize those technologies in an experiment. After application of the inclusion criteria, a total of 24 articles were included in this review.

\section{Descriptive Synthesis}

The raters coded each article by the following variables: (a) number of participants; (b) participants characteristics (age, gender, diagnosis); (c) dependent variable; (d) independent variable, (e) technology utilized (description of the AR technology); (f) experimental design; and (g) study outcomes. Raters coded the total number of participants including both the participants with ASD and without ASD. Raters provided a narrative description of the dependent variables, independent variables, and technology used. Raters coded the experimental design as either group experimental, quasi-experimental, or single-case experimental designs. Finally, raters coded the study outcomes according to how the author(s) reported the outcomes for the target dependent variable(s).

\section{Quality Evaluation Method}

Articles were group based on the experimental design (i.e., single-case research versus group experimental/quasiexperimental) to facilitate the quality evaluation. The two lead authors then evaluated each study according to corresponding rubric developed by Reichow et al. (2008) evaluative method single case or group-experimental research design. Reichow's evaluative method was chosen in comparison to other quality evaluative method (e.g., Center for Exceptional Children Standards) since it includes procedures to evaluate both single-case and group experimental research, evaluates internal and external validity, and was specifically developed for research specific to individuals with autism (Cook et al., 2015; Reichow, 2008). Additionally, Reichow's evaluative method has been well established in the literature to aid in the identification of practices that meets the standards to be classified as an evidence-based practice (EBP; Lynch et al., 2018; Reichow, 2011).

\section{Interrater Reliability}


Search and Inclusion Criteria. During the review for inclusion, two raters coded $100 \%$ of the articles $(n=74)$. To evaluate the reliability of the application of the inclusion and exclusion criteria, interrater reliability (IRR) was calculated using the percent agreement by dividing the total number of agreements by the total number of agreements plus disagreements and then multiplying by 100 to obtain a percentage. Agreement on inclusion was obtained on $89.19 \%$ of the studies $(n=66)$. Disagreements were reviewed and discussed by the raters until agreement was established for a final agreement of $100 \%$.

Data Extraction. Two raters independently coded $50 \%$ of the included articles $(n=24)$. Each article was coded across three categories with a total of 36 items for which reliability was evaluated (i.e., 12 articles with three categories each). Agreement was established on 33 of the items. And IRR was calculated using the percentage of agreement by dividing the total number of items with agreement and by the total number of items and then multiplying by 100 to obtain a percentage. The initial IRR was $91.67 \%$. Disagreements were reviewed by the raters and discussed for a final IRR of $100 \%$. The final table was then evaluated for accuracy by the remaining authors to ensure accuracy of the table.

Quality Evaluation. Twelve studies of the 24 articles (50\%) were independently reviewed by the two lead authors to establish IRR. The 12 articles included seven group experimental/quasi-experimental design studies and four single-case research studies. There were 12 indicators per article for a total of 24 items for which reliability was evaluated. Agreement was established on 21 of the 24 total items (88\%). Disagreements were discussed by the authors until a consensus for a final IRR of $100 \%$.

\section{Results}

The 24 articles included in this review were summarized by dependent variable, intervention components, behavioral components, and technology used. Table 1 provides the data summary of each study.

Participants. Across the 24 included studies there were a total of 882 participants (excluding the staff participants included in Smith et al., 2021a) with an approximate mean age of 19.77 (range $=4$ to 29.4). The majority of the included participants were high to moderate functioning levels.

Dependent variables. Of the 24 studies, $41.67 \%(n=10)$ taught vocational related skills. Specifically, nine of these studies (e.g., Burket et al., 2018; Genova et al., 2021; Smith et al., 2014) targeted job interview skills and one targeted general vocational skills (i.e., Bozgeyikil et at., 2017). Of the functional behaviors targeted, 29.17\% $(n=7)$ of the studies focused on the treatment of problem behavior, such as the treatment of fears, phobias (e.g., Maskey et al., 2014; Maskey et al., 2019a; Meindl et al., 2019), or hypersensitivity (i.e., Johnston et al., 2020). Four (16.67\%) studies focused on safety related skills, such as pedestrian safety (i.e., Dixon et al., 2019), driving skills (i.e., Cox et al., 2017; Wade et al., 2016), and transportation use (i.e., Miller et al., 2020; Simões et al., 2018). Two studies targeted general functioning skills, such as match to sample skills (i.e., Hu \& Han, 2019) and understanding the context and characteristics of common objects (i.e., Wang \& Reid, 2013). Lastly, only one study focused on increasing exercise engagement (i.e., McMahon et al., 2020).

Behavior analytic components embedded within VR. A combination of behavior analytic components, such as antecedent interventions, prompting, reinforcement, or corrective feedback, were utilized by all the included studies. For nine of the studies (37.5\%) the VR system primarily provided the learning stimuli, prompts, and consequence variables (e.g., reinforcement or feedback) and although in some cases a researcher or therapist 
provided pre-training on the use of the VR system. For five of the studies (20.83\%) a combination of the VR system and therapist implementation was used. For example, for most of the studies utilizing VR within the context of job interview training, the VR system was primarily used for practice interviews and additional instruction was provided by a therapist on related interview skills (e.g., Smith et al., 2021a; Strickland et al., 2013). Lastly, eight studies (33.33\%) the VR system was utilized primarily for the learning stimuli needed for teaching the targeted skill with a therapist delivering instruction, prompting, and reinforcement. For example, Dixon et al. (2019) used the VR system within the context of pedestrian safety (visual and auditory stimuli) with a therapist delivering questions related to the safety of the situation (e.g., "Is there a moving car?") and providing reinforcement for the participants responses.

VR Technology. All papers used software to create the virtual environments, but some used additional hardware displays and interfaces to increase the level of immersion. A non-immersive VR was the most commonly utilized configuration, which was used by $41.67 \%$ of the included studies $(n=10)$. This type of VR configuration is the least immersive and generally relied on a standard desktop sized computer monitor (i.e., size range) with basic inputs from the user (e.g., desktop keyboard or controller; Bamodu, \& Ye, 2013). The second most utilized VR platform was a semi-immersive VR which was used by $33.33 \%(n=8)$. This configuration relied on external equipment, such as sensors for interaction (e.g., XBOX Kinect, Leap Motion) and projectors or large screens to display the VR simulation (e.g., Blue Room advanced VRE) to create a sense of deeper immersion and interactivity within a VR simulation (Bamodu, \& Ye, 2013). Lastly full immersive VR was used by $25 \%(n=6)$ of the included studies. This set up entailed both the use of advanced VR technology (e.g., motion tracking, head mounted display, Oculus Touch controllers) with the use of software (e.g., Unity Game engine) to create the more advanced 3D VR environments (Bamodu, \& Ye, 2013).

Quality Ratings and evaluation of evidence. There were 18 group experimental design studies and six single-case experimental design studies. Overall, the raters identified three (12.5\%) of the studies as meeting criteria to be classified as "strong" and nine (37.5\%) of the studies as meeting criteria to be classified as "adequate". The remaining studies $(12 ; 50 \%)$ did not meet criteria and cannot offer evidence towards the research question. Of the 18 group experimental design studies the raters classified two (.83\%) as "strong", six (25\%) as "adequate" and ten $(41.67 \%)$ as "weak". Of the six single-case experimental design studies, the raters classified one (.42\%) as "strong", three (12.5\%) as "adequate" and two (.83\%) as "weak".

Taken as a whole, the three studies (Cox et al., 2017; Hu \& Han, 2019; Wade et al., 2013) identified as "strong" quality studies were conducted by three different research teams, at three different locations, with 74 different participants and meet the qualifications to be considered a promising practice.

\section{Discussion}

The primary aim of this review was to synthesize the literature based on the use of VR interventions for adaptive and functional behavior for individuals with autism. The secondary aim of this review was to evaluate the quality of the studies to help guide future research and practice applications. A total of 24 studies met the criteria of inclusion for this review. Of those studies, ten targeted vocational related skills, seven targeted functional behaviors (e.g., problem behavior treatment, hypersensitivity, phobias), four targeted safety skills (e.g., driving, airplane travel, pedestrian safety), two studies targeted general functional skills, and one targeted exercise engagement. In terms of quality ratings, only three of the studies met the three quality criteria for a classification 
of "strong". This indicates a need for replication of both single case and group experimental design, as well as an increase in the rigor of quality design methodology. Further, since these studies did not incorporate full immersive VR, this also highlights an area of need for quality research design and replication.

This review highlights several benefits for the use of VR based interventions for individuals with autism. First, the ability to create environments conducive to safe practice for the development of safety skills, such as driving safety and pedestrian safety skills. In particular, VR environments can reduce the risks associated skill acquisition that might not be feasible in the real-world environments. For example, when practicing safely walking across the street in a VR environment, there are no real risk if the user does not wait for the crosswalk sign to signal as compared to the real environment, where an individual could be hit by a car.

Another potential benefit of VR based interventions are the ability to customize the user's intervention based on their progress for skill acquisition, such as embedding prompts to help highlight the salient cues in the environment that should evoke a specific behavior response from the user. For example, Cox et al. (2017) included extra stimulus cues within the VR driving simulation based on user eye gaze to highlight driving hazards that should evoke driver attention and defensive driving maneuvers. This type of included component can potentially help ensure the VR interaction can individualize to the user, thus providing a more tailored intervention and user experience.

VR interventions can also allow for extra practice and a variety of exemplars to better promote generalization of skills (multiple exemplar training study). Further, VR can also easily allow for generalization to the natural environment since it allows for programming of the relevant stimuli that would occur within the natural environment (Stokes \& Baer, 1977). For example, Miller et al. (2020) included programming for generalization within the sessions of the study. Specifically, this study conducted the last session of the study at the airport to provide a real-world rehearsal of the air travel skills targeted during the VR-based intervention. This study highlights the utility and efficacy of VR based interventions as well as the need to evaluate the transfer of skills to the "real" environment. However, given the lack of assessment of generalization to real-environments from the studies included in this review, more analysis is needed to evaluate the effects of generalization on VR-trained skills.

Lastly, some of the studies included in this review indicated the effectiveness of using lower cost VR systems, which may increase the feasibly of VR-based interventions within clinical applications. For example, Miller et al. (2020) used an iPhone X with Google Cardboard device to create a virtual air travel experience. And several studies used a commercially available internet software program (i.e., Molly Porter by SIMmerson Immersive Simulations) to provide mock interviews for developing interview skills (i.e., Genova et al., 2021; Humm et al., 2014; Smith et al., 2014; Smith et al., 2021a, 2021b; Ward \& Esposito et al., 2018). Although low tech solutions may be readily available, research is still needed to help evaluate the costs and benefits of the various VR technology as it relates to skills being taught, the needs of the individual, and the programming of relevant environmental variables to help best promote generalization of skills to real world environments.

While the current research evaluated in this review indicates that VR is a conducive platform complementary for the integration of behavior analytic strategies to develop effective interventions, there are a few considerations worthy of discussion. First, only three studies met the criteria for a classification of "strong" quality standards. This indicates a need for further replication of VR-based interventions that focus on teaching functional and adaptive skills. 
Second, there is a need for decision making frameworks to help inform practitioners and service providers which equipment options allow for individualization or what technology options best align to various characteristics and needs of the individuals we serve. For example, Simões et al. (2018) provided differentiation across the technology used. Specifically, four of the participants in the study did not use the VR head-mounted display due to vision impairments, however the desktop configuration was still conducive for those users to participate in the VR intervention. This highlights the need for clear decision-making framework for technology selected in VR-based interventions.

Third, there is a need for cross field collaboration to ensure that VR interventions have the programming capacity for individualization, systematic teaching procedures, and reinforcement contingencies that are transferable to the real environments. In many of the studies included in this review, therapist/researchers were still providing prompts and reinforcement rather than these elements being seamlessly incorporated into the VR system. This may indicate that there was a lack of collaboration across technology developers and behavior analysts. As such, future research should consider the benefits of cross-field collaboration to improve the quality and efficacy of VR-based interventions.

Finally, there is a need to evaluate other skills that fall within the domain of adaptive and functional behaviors, where VR could provide a better context for developing effective interventions. Given the few areas of safety skills addressed in the current literature, this seems like an obvious area that could benefit individuals who are working to develop these functional skills. For example, abduction prevention could be an area where VR base interventions might provide for more effective training, as compared to role playing or social stories-based interventions, since the virtual environment could include relevant signals with multiple exemplars and provide practice opportunities (e.g., Ledbetter-Cho et al., 2016).

\section{Implication For Practice And Conclusion}

For practitioners, it is important to highlight the use of EBPs when developing interventions for individuals with autism. Given the range of technology options for VR-based intervention, consideration of prerequisite skills for both the use of technology and the skill that is targeted within the intervention. Thus, assessment should be utilized to help guide the intervention plans. For example, if using VR goggles, it would be important to do some direct assessment to ensure the user has the necessary skills and that the VR experience is enjoyable and does not cause issues, such as motion sickness. Practitioners would also want to be sure that generalization of the skill is accounted for within the intervention and transfers easily to the real world. This may also require incorporating other stakeholders within the intervention phases to ensure the technology used is feasible for everyone involved. As VR technology continues to advance, research is needed to help provide a clear framework for collaboration and decision making to help progress and extend VR-based interventions.

\section{References}

Bamodu, O., \& Ye, X. M. (2013). Virtual reality and virtual reality system components. In Advanced Materials Research, 765, 1169-1172.

https://doi.org/10.4028/www.scientific.net/AMR.765-767.1169 
Barton, E. E., Pustejovsky, J. E., Maggin, D. M., \& Reichow, B. (2017). Technology-aided instruction and intervention for students with ASD: A meta-analysis using novel methods of estimating effect sizes for single-case research. Remedial and Special Education, 38(6), 371-386.

http://dx.doi.org.libweb.lib.utsa.edu/10.1177/0741932517729508

*Bozgeyikli, L., Bozgeyikli, E., Raij, A., Alqasemi, R., Katkoori, S., \& Dubey, R. (2017). Vocational rehabilitation of individuals with autism spectrum disorder with virtual reality. ACM Transactions on Accessible Computing (TACCESS), 10(2), 1-25. https://doi.org/10.1145/3046786

*Burke, S. L., Bresnahan, T., Li, T., Epnere, K., Rizzo, A., Partin, M., ... \& Trimmer, M. (2018).

Using virtual interactive training agents (ViTA) with adults with autism and other developmental disabilities. Journal of autism and developmental disorders, 48(3), 905-912. https://doi.org/10.1007/s10803-017-3374-Z

*Burke, S. L., Li, T., Grudzien, A., \& Garcia, S. (2021). Brief report: Improving employment

interview self-efficacy among adults with autism and other developmental disabilities using virtual interactive training agents (ViTA). Journal of Autism and Developmental Disorders, 51(2), 741-748.

https://doi.org/10.1007/s10803-020-04571-8

Cooper, J. O., Heron, T. E., \& Heward, W. L. (2020). Applied Behavior Analysis, $3^{\text {rd }}$ Edition.

Pearson.

*Cox, D. J., Brown, T., Ross, V., Moncrief, M., Schmitt, R., Gaffney, G., \& Reeve, R. (2017). Can youth with autism spectrum disorder use virtual reality driving simulation training to evaluate and improve driving performance? An exploratory study. Journal of Autism and Developmental Disorders, 47(8), 2544-2555.

https://doi.org/ 10.1007/s10803-017-3164-7

Dechsling, A., Shic, F., Zhang, D., Marschik, P. B., Esposito, G., Orm, S., Sütterlin, S., Kalandadze, T., Øien, R. A., \& Nordahl-Hansen, A. (2021). Virtual reality and naturalistic developmental behavioral interventions for children with autism spectrum disorder. Research in Developmental Disabilities, 111, 103885.

https://doi.org/10.1016/j.ridd.2021.103885

*Dixon, D. R., Miyake, C. J., Nohelty, K., Novack, M. N., \& Granpeesheh, D. (2020). Evaluation of an immersive virtual reality safety training used to teach pedestrian skills to children with autism spectrum disorder. Behavior Analysis in Practice, 13(3), 631-640. https://doi.org/10.1007/s40617-019-00401-1

Di Natale, A. F., Repetto, C., Riva, G., \& Villani, D. (2020). Immersive virtual reality in K-12 and higher education: A 10-year systematic review of empirical research. British Journal of Educational Technology, 51(6), 2006-2033. https://doi.org/10.1111/bjet.13030

*Genova, H. M., Lancaster, K., Morecraft, J., Haas, M., Edwards, A., DiBenedetto, M., ... \& Smith, M. J. (2021). A pilot RCT of virtual reality job interview training in transition-age youth on the autism spectrum. Research in Autism Spectrum Disorders, 89, 101878. https://doi.org/10.1016/j.rasd.2021.101878 
Hume, K., Steinbrenner, J. R., Odom, S. L., Morin, K. L., Nowell, S. W., Tomaszewski, B., Szendrey, S., Mclntyre, N. S., Yücesoy-Özkan, S., \& Savage, M. N. (2021). Evidence-based practices for children, youth, and young adults with autism: Third generation review. Journal of Autism and Developmental Disorders, 51, 4013-4032. https://doi.org/10.1007/s10803-020-04844-2

*Hu, X., \& Han, Z. R. (2019). Effects of gesture-based match-to-sample instruction via virtual reality technology for Chinese students with autism spectrum disorders. International Journal of Developmental Disabilities, 65(5), 327336. https://doi.org/10.1080/20473869.2019.1602350

*Humm, L.B., Olsen, D., Morris, B.E., Fleming, M., \& Smith, M. (2014). Simulated job interview improves skills for adults with serious mental illnesses. Studies in health technology and informatics, 199, 50.

https://dio/org/10.3233/978-1-61499-401-5-50

Irish, J. E. (2013). Can I sit here? A review of the literature supporting the use of single-user virtual environments to help adolescents with autism learn appropriate social communication skills. Computers in Human Behavior, 29(5), A17-A24. https://doi.org/10.1016/j.chb.2012.12.031

*Johnston, D., Egermann, H., \& Kearney, G. (2020). SoundFields: A virtual reality game designed to address auditory hypersensitivity in individuals with autism spectrum disorder. Applied Sciences, 10(9), 2996. https://doi.org/10.3390/app10092996

Kratochwill, T. R., Hitchcock, J. H., Horner, R. H., Levin, J. R., Odom, S. L., Rindskopf, D. M., \& Shadish, W. R. (2013). Single-case intervention research design standards. Remedial and Special Education, 34(1), 26-38. https://doi.org/10.1177\%2F0741932512452794

Leaf, J. B., Cihon, J. H., Ferguson, J. L., Milne, C. M., Leaf, R., \& McEachin, J. (2020). Advances in our understanding of behavioral intervention: 1980 to 2020 for individuals diagnosed with autism spectrum disorder. Journal of Autism and Developmental Disorders, 4395-4410. https://doi.org/10.1007/s10803-020-04481-9

Ledbetter-Cho, K., Lang, R., Davenport, K., Moore, M., Lee, A., O'Reilly, M., Watkins, L., Falcomata, T. (2016). Behavioral skills training to improve the abduction-prevention skills of children with autism. Behavior Analysis in Practice, 9(3), 266-70. doi: 10.1007/s40617-016-0128-x. PMID: 27622133; PMCID: PMC4999365.

Lynch, Y., McCleary, M., \& Smith, M. (2018). Instructional strategies used in direct AAC interventions with children to support graphic symbol learning: A systematic review. Child Language Teaching and Therapy, 34(1), 23-36.

Maenner, M. J., Shaw, K. A., Bakian, A. V., Bilder, D. A., Durkin, M. S., Esler, A., ... \& Cogswell, M. E. (2021). Prevalence and characteristics of autism spectrum disorder among children aged 8 years-autism and developmental disabilities monitoring network, 11 sites, united states, 2018. MMWR Surveillance Summaries, 70(11), 1. https://doi.org/10.15585/mmwr.ss7011a1

*Maskey, M., Lowry, J., Rodgers, J., McConachie, H., \& Parr, J. R. (2014). Reducing specific phobia/fear in young people with autism spectrum disorders (ASDs) through a virtual reality environment intervention. PloS one, 9(7), e100374.

*Maskey, M., McConachie, H., Rodgers, J., Grahame, V., Maxwell, J., Tavernor, L., \& Parr, J. R. (2019). An intervention for fears and phobias in young people with autism spectrum disorders using flat screen computer- 
delivered virtual reality and cognitive behaviour therapy. Research in Autism Spectrum Disorders, 59, 58-67.

https://doi.org/10.1016/j.rasd.2018.11.005

*Maskey, M., Rodgers, J., Grahame, V., Glod, M., Honey, E., Kinnear, J., ... \& Parr, J. R.

(2019). A randomised controlled feasibility trial of immersive virtual reality treatment with cognitive behaviour therapy for specific phobias in young people with autism spectrum disorder. Journal of Autism and Developmental Disorders, 49(5), 1912-1927. https://doi.org/10.1007/s10803-018-3861-x

*Maskey, M., Rodgers, J., Ingham, B., Freeston, M., Evans, G., Labus, M., \& Parr, J. R. (2019).

Using virtual reality environments to augment cognitive behavioral therapy for fears and phobias in autistic adults. Autism in Adulthood, 1(2), 134-145.

https://doi.org/ 10.1089/aut.2018.0019

*McMahon, D. D., Barrio, B., McMahon, A. K., Tutt, K., \& Firestone, J. (2020). Virtual reality

exercise games for high school students with intellectual and developmental disabilities. Journal of Special Education Technology, 35(2), 87-96. https://doi.org/10.1177/0162643419836416

McMahon, D., Cihak, D. F., \& Wright, R. (2015). Augmented reality as a navigation tool to employment opportunities for postsecondary education students with intellectual disabilities and autism. Journal of Research on Technology in Education, 47(3), 157-172. https://doi.org/10.1080/153 91523.2015.1047698

*Meindl, J. N., Saba, S., Gray, M., Stuebing, L., \& Jarvis, A. (2019). Reducing blood draw phobia in an adult with autism spectrum disorder using low-cost virtual reality exposure therapy. Journal of Applied Research in Intellectual Disabilities, 32(6), 1446-1452.

https://doi.org/10.1111/jar.12637

*Miller, I. T., Wiederhold, B. K., Miller, C. S., \& Wiederhold, M. D. (2020). Virtual reality air travel training with children on the autism spectrum: A preliminary report. Cyberpsychology, Behavior, and Social Networking, 23(1), 10-15.

https://doi.org/ 10.1089/cyber.2019.0093

Parsons, S., \& Mitchell, P. (2002). The potential of virtual reality in social skills training for people with autistic spectrum disorders. Journal of Intellectual Disability Research, 46(5), 430-443. https://doi.org/10.1046/j.13652788.2002.00425.x

Reichow, B., Volkmar, F. R., \& Cicchetti, D. V. (2008). Development of the evaluative method for evaluating and determining evidence-based practices in autism. Journal of Autism and Developmental Disorders, 38(7), 13111319. https://doi.org/10.1007/s10803-007-0517-7

Reichow, B. (2012). Overview of meta-analyses on early intensive behavioral intervention for young children with autism spectrum disorders. Journal of autism and developmental disorders, 42(4), 512-520. 
* Simões, M., Bernardes, M., Barros, F., \& Castelo-Branco, M. (2018). Virtual travel training for autism spectrum disorder: proof-of-concept interventional study. JMIR Serious Games, 6(1), e8428.

https://doi.org/10.2196/preprints.8428

*Smith, M. J., Ginger, E. J., Wright, K., Wright, M. A., Taylor, J. L., Humm, L. B., ... \& Fleming, M. F. (2014). Virtual reality job interview training in adults with autism spectrum disorder. Journal of autism and developmental disorders, 44(10), 2450-2463.

https://doi.org/10.1007/s10803-014-2113-y

*Smith, M. J., Sherwood, K., Ross, B., Smith, J. D., DaWalt, L., Bishop, L., ... \& Steacy, C. (2021). Virtual interview training for autistic transition age youth: A randomized controlled feasibility and effectiveness trial. Autism, 25(6) 1536-1552. https://doi.org/10.1177/1362361321989928

*Smith, M. J., Smith, J. D., Jordan, N., Sherwood, K., McRobert, E., Ross, B., ... \& Atkins, M. S. (2021). Virtual Reality Job Interview Training in Transition Services: Results of a Single-Arm, Noncontrolled EffectivenessImplementation Hybrid Trial. Journal of Special Education Technology, 36(1), 3-17. https://doi.org/10.1177/0162643420960093

*Strickland, D. C., Coles, C. D., \& Southern, L. B. (2013). JobTIPS: A transition to employment program for individuals with autism spectrum disorders. Journal of Autism and Developmental Disorders, 43(10), $2472-2483$.

https://doi.org/ 10.1007/s10803-013-1800-4

Thai, E., \& Nathan-Roberts, D. (2018). Social skill focuses of virtual reality systems for individuals diagnosed with autism spectrum disorder: A systematic review. In Proceedings of the Human Factors and Ergonomics Society Annual Meeting, 62(1), 1469 - 1473. doi: 10.1177/1541931218621333

Available at: http://works.bepress.com/dan_nathan-roberts/17/

Tiura, M., Kim, J., Detmers, D., \& Baldi, H. (2017). Predictors of longitudinal ABA treatment outcomes for children with autism: A growth curve analysis. Research in Developmental Disabilities, 70, 185-197.

https://doi.org/10.1016/j.ridd.2017.09.008

Vasquez, E., Nagendran, A., Welch, G. F., Marino, M. T., Hughes, D. E., Koch, A., \& Delisio, L. (2015). Virtual learning environments for students with disabilities: A review and analysis of the empirical literature and two case studies. Rural Special Education Quarterly, 34(3), 26-32. https://doi.org/10.1177/875687051503400306

*Wade, J., Zhang, L., Bian, D., Fan, J., Swanson, A., Weitlauf, A., ... \& Sarkar, N. (2016). A gaze-contingent adaptive virtual reality driving environment for intervention in individuals with autism spectrum disorders. ACM Transactions on Interactive Intelligent Systems (TiiS), 6(1), 1-23. https://doi.org/10.1145/2892636

*Wang, M., \& Reid, D. (2013). Using the virtual reality-cognitive rehabilitation approach to improve contextual processing in children with autism. The Scientific World Journal, 2013. http://dx.doi.org/10.1155/2013/716890

*Ward, D. M., \& Esposito, M. K. (2019). Virtual reality in transition program for adults with autism: Self-efficacy, confidence, and interview skills. Contemporary School Psychology, 23(4), 423-431. 
Wills, H. P., \& Mason, B. A. (2014). Implementation of a self-monitoring application to improve on-task behavior: A high school pilot study. Journal of Behavioral Education, 23(4), 421-434. https://doi.org/10.1007/s10864-0149204-x

\section{Declarations}

We have no known conflict of interest to disclose.

Correspondence concerning this article should be addressed to Amarie Carnett, Faculty of Educational, P.O. Box 600, Wellington 6140, New Zealand. Email: amarie.carnett@vuw.ac.nz

Contributions: All of the authors equally contributed to the idea conceptualization for the manuscript as the manuscript represents transdisciplinary concepts. Amarie Carnett, Leslie Neely, and Marie Kirkpatrick lead the writing of the manuscript for the behavior analytic content and conducted the quality review. Siobhan Gardiner conducted the searches and led the development of Table 1. John Quarles and Kameron Christopher led the writing of the manuscript for the virtual reality content.

\section{Tables}

\section{Table 1.}

Descriptive Synthesis 


\section{Citation Dependent Variable Intervention}

Bozgeyikil (1) Level scores

et al.

(2017)

\section{measured via 6}

vocational skills (2)

Participant self-rated

(tiredness,

immersion, motion

sickness, satisfaction,

effective training,

reasonable design,

and accuracy) via

a modified version of

Loewenthal's core

elements of the

gaming experience

questionnaire, (3)

Follow-up data on the

6 vocational skills

were collected via a

survey by the job

trainers and, (4)

Social validity was

collected via

qualitative survey

data.

Burke et

al. (2018)

Interview skills

measured using the

Marino Interview

Assessment Scale

Measures
The user completed

six job training

modules (cleaning,

environmental

awareness, loading,

money

management,

shelving, social

skills). Each module

began with a

tutorial provided by

a virtual instruction

to explained and

show the user how

to perform the task.

This was then

proceeded by two

additional levels

increasing in

difficulty.

Intervention
involved
participants
completing job
interview
coursework with the
final 5 sessions
dedicated to ViTA
virtual interview.
Participants
completed four
virtual interviews.

Antecedent

Component: Module

tutorial delivered by virtual

instructor who provided

verbal instructions and

modeling of the skill

without any distractors.

Assistive prompts via VR. If

user did not perform task

within a minute, a prompt

(verbal instructions,

pictographs, and

animations) was given.

\section{Consequence}

Component: Corrective

feedback delivered in the

form of pictures via VR, for

example stating, "well

done" or "collision".
VR Technology

Fully Immersive VR: VR2200

Head Mounted Display

(HMD), an optical motion

tracking system with 12

OptiTrack Flex:V100 cameras

that track an area of $8 \mathrm{ft}$ by

$8 \mathrm{ft}$, a large 180。 curved

curtain screen, touch screen

controls, tangible objects

equipped with optical

markers that can be tracked

by the system in real time,

and a remote control panel

for the job trainers.

The software was developed using the Unity game engine and run via a desktop

computer.

\section{Antecedent \\ Component: Staff}

provide instruction on

interview strategies and

equipment training for

ViTA to user.

\section{Consequence}

Component: Corrective feedback delivered via VR system.

Other Component: Roleplay of interviews via the VR system
Burke et

al. (2021)
(1) Interview skills

measured using the

Marino interview

assessment scale

measures (2) Self-

efficacy measured

using the ViTA self-

efficacy scale consisting of three

subscales (strength, career decisions, and general).

\author{
Participants \\ accessed multi- \\ media interview \\ skills content from \\ their home \\ computer and \\ afterward \\ completed a \\ simulated online \\ interview (ViTA \\ system). \\ Participants \\ participated in four \\ ViTA interview \\ sessions, one initial
}

\section{Antecedent \\ Component: Staff}

provide instruction on

interview strategies and

equipment training for

ViTA to user.

Consequence

Components: Corrective

feedback delivered via VR system.

Other Component: Roleplay of interviews via the VR system.
Semi-immersive VR: Virtual interactive training agent (ViTA) system. ViTA utilizes the Unity Game Engine as the sole core of the ViTA software. The ViTA lab utilizes 3 different cameras (a HD video camera to record interviews, a web camera used as a backup camera, and an XBOX GEN 1 KINECT camera system used to track facial expressions. The VR was delivered using a 60-70inch Samsung HD flat-screen TV. A custom networked three PC server cabinet was used to run the ViTA software, camera system, and automatic backup and shutdown system.

Non-immersive VR: Virtual interactive training agent (ViTA) system. The apparatus consisted of a HD LCD monitor with the minimum equipment needed composing of a laptop (recommended) or another computer, 24 " HD LCD monitor or larger, feature cable, lapel microphone, wireless mouse and keyboard HDMI Cable or VGA, $3.5 \mathrm{~mm}$ multimedia speakers, $3.5 \mathrm{~mm}$ lapel microphone, wireless mouse, 
face-to-face

interview, and one

final face-to-face

interview at

completion of

sessions

(approximately 22

weeks).

Cox et al., (1) Driving-specific (2017) executive function abilities, (2) Tactical driving skills and (3) Eye tracking

Participants were randomized to either Routine Training (the statespecific department of motor vehicle training manual) Standard VRDST, Automated VRDST, or Eye Tracking VRDST.

Standard VRDST:

During each

session, the trainer would first

demonstrate the

task to the

participant, and

then monitor

participant

performance while

providing continual

verbal feedback.

The Automated

VRDST: identical to

Standard VRDST

with the simulator's

computerized voice

provided real- time

auditory feedback.

Eye Tracking

VRDST: similar to

the Standard

VRDST with the

addition of feedback

from the eye tracker

(glasses) options

that modelled

exactly where the

participant should

look while driving.

Once a segment

was completed, the

trainer and

participant would

review their

performance. and a wireless keyboard to allow for the remote operation of the Interview Scenario.

Antecedent Component: In Standard condition, the trainer demonstrated first to participant.

\section{Consequence}

Component: Feedback (both corrective and positive vocal praise) was delivered via a trainer in Standard condition and feedback was delivered via VR in Automated conditions.
Semi-immersive VR: Driver Guidance System (DGS-78) VRDS is a realistic driver's cockpit with side and rearview mirrors. The driver's view is projected onto a 2.44 $\mathrm{m}(8 \mathrm{ft})$ diameter, $210^{\circ}$ curved screen.

Eye-tracking glasses (Mobile Eye XG).
Dixon et

al. (2018)
Percentage of correct response for safe street crossing.

\section{Intervention}

entailed teaching safe street crossing (identifying whether it was safe to cross the road or not) in the natural environment. Training sessions

\section{Antecedent}

Component: Flexible

prompt fading was used by the therapist to teach the participants the approach responses for all three steps.
Fully Immersive VR: Oculus Rift (Version CV1) headset and sensors. The Oculus Rift was connected to a laptop. The immersive VR environment consisted of 360-degree videos of real streets from the participants' community. Videos were 
entailed showing a video clips of safe and unsafe crossing situations using immersive VR. Flexible prompting and fading procedures were used to teach the participant the responses (looking left and right, responding to "Is there a car moving?", and responding to "Is it safe to cross?").

Genova et (1) Job interview əl. (2021) skills measured via the Mock Interview Rating Scale, (2) Likelihood to be hired, (3) Interviewee performance measured via composite score, (4) Job interview selfefficacy and anxiety measured via selfreport questionnaires.
Hu \& Han (2019)
(1) Percentage of correct matching responses, (2) Percentage of task engagement (physical attendance to the match-to-sample tasks), and (3) Social validity collected via teacher survey.
Participants used the Virtual Reality
Job Interview
Training (VR-JIT)
system with
includes e-learning
component to teach
job interviewing
skills (getting ready
for the interview,
being on time and
acting
professionally), as
well as virtual
practice interviews.
Sessions consisted
of three levels of

\section{Consequence \\ Component: Three types of feedback were provided (1) real-time feedback through the use of a virtual \\ "Job Coach" (non-verbal cues (thumbs up/down, clapping) after answering a question, (2) a quantitative performance-based score given upon the conclusion of each interview, (3) the interventionist reviewed the interview transcript with the participant to provide feedback on how they performed.}

difficultly.

Participants

practiced job

interviews with a

virtual interviewer.

Discrete-trial

teaching. The

computer

application

randomly presented

15 out of the total

30 pairs of

associated items.

Each pair was

presented as one

trial at a time. After

the software

presented the

pictures with verbal

stimulus

(directions) the

participant was

given 3 s to respond

using the Leap

Motion controller.

Th researcher

provided prompting

if a response did not occur following the 3s. The software

\section{Antecedent Component: Each session began with attending skills and establishing rapport with the researcher. Pretraining for VR system utilized an errorless learning procedure by the researcher for basic operation.}

A visual cue serving as a prompt was delivered by the system if participant did not respond within 5s.

\section{Consequence}

Component: During the intervention reinforcement was delivered via VR (smiley face and an auditory reinforcing statement). Corrective feedback was provided if the student failed to
Consequence

Component: Reinforcement

was provided by the

therapist regardless of a

correct or a prompted

response, verbal praise

was provided after each

step, verbal praise or a

token was provided at the

end of each trial, and

access to a preferred

activity was provided after

each session based on the

participant's preference. recorded using a Samsung

Gear 360 camera attached to a 4 -ft. $(1.2 \mathrm{~m})$ monopod. A low-profile monopod was used to reduce visual distractions in the videos. The videos were hosted on YouTube.
Non-immersive VR: VR-JIT system (developed by SIMmersion LLC) is a computerized job interview simulator delivered via the internet. Other equipment used not specified.

\section{Semi-immersive VR: PC} laptop and a Leap Motion controller.

The match-to-sample software program was developed for the purpose of this study and not commercially available. 
Humm et

l. (2014)

(1) Role play skills

scores, (2) Selfconfidence measures,

(3) Helpfulness, (4)

Enjoyableness, and

(5) Ease of used.

Items 2-5 all

measured via the

Training Experience

questionnaire.

「ohnston

et al.

(2020)

(1) Anxiety measured

via the Modified

Smiley-Face provided feedback

based on the

accuracy of the

response (e.g.,

corrective or

praise).

Virtual job interview

training program

(Job Interview

Training with Molly

Porter) that

includes user-driven

elearning, an

interactive job

application, and

practice interview

simulation with a

virtual interviewer.

Assessment Scale, and (2) Tracked participant interaction with target auditory stimuli.

respond correctly with the visual cue, the system would display a crying face with the auditory statement of 'Try again'.

\section{Consequence}

Component: Feedback delivered via VR to reinforce appropriate demonstration of job interviewing skills.

\author{
Semi-immersive \\ VR: Computer based VR \\ System. VR-VIT with Molly \\ Porter from \\ SIMmersion PeopleSim ${ }^{\mathrm{TM}}$ \\ technology.
}

The intervention was deviled using the VR game called SoundFields. During the sessions, participant engaged with a non-playable character who provides direction within the game (as a guide). Across the sessions, a spatial audio exposure hierarchy was programed into the VR environment.
Consequence Component: Positive reinforcement for interacting with aversive auditory stimuli and utilization of token economy within VR.

\begin{abstract}
Fully Immersive
VR: SoundFields is the prototype of an individual interactive virtual reality game. All visual stimuli were rendered using the Oculus Rift CV1 head mounted display (HMD). Head tracking was also achieved using the HMD, with motion tracking of participant position calculated by the Oculus Rift sensors. Player input was achieved using the Oculus Touch controllers. Audio was presented to the participant using Sennheiser HD-650 headphones.
\end{abstract}

A combination of CBT and gradual exposure in VR environments (Blue Room) were provided during the intervention. Each child had one assessment and preparation session at home where they were coached on techniques to use when experiencing anxiety (CBT). This was then followed by a VRE exposure sessions. For each participant the VRE scene was individualized based on their phobia).

A combination of CBT and gradual exposure in VR environments (computer delivered

Antecedent
Component: Presession
coaching was provided by a
therapist for relaxation
techniques in a relaxing
VRE scene prior to the
phobia treatment.

Systematic desensitization/ extinction through graded exposure of Phobia.

Other Component: Session debriefing with the therapist and family to discuss planning for real life exposure to their phobia.

\section{Semi-immersive} 'Blue Room', an advanced computer generated VRE. The Blue Room uses audiovisual images projected onto the walls and ceilings of a 360-degree seamless screened room.

iPad for therapist use to operate the graded exposure on the computer-generated scene.
VR: Immersive technology

\author{
Antecedent \\ Component: Presession \\ coaching was provided by a \\ therapist for relaxation \\ techniques in a relaxing
}

Non-immersive VR: For the VR software, a Third Eye Neurotech programmer was used. The computer monitor had a diagonal screen size of

\begin{tabular}{ll}
\hline Maskey et & (1) Anxiety symptoms \\
al. & measured the via \\
(2019a) & Spence Children's \\
& Anxiety Scale-parent \\
& version and child
\end{tabular}


version, (2) Target behaviors related to handling the situation that caused anxiety, and (3) Confidence rating scale (feelings thermometer).
Maskey et

al.

(2019b)
(1) Target behavior ratings measured via the recorded rating of change over time in the specific phobia, (2) Anxiety measured via the Spence Children's Anxiety Scale-parent version and child version, (3) Assessment of fear measured via the Fear Survey Schedule for Children-revised, and (4) increase in child's participation in a range of community activities measured via the Children's Assessment of Participation and Enjoyment.

Maskey et al. (2019c) sessions) were provided during the intervention. Each child had one assessment and preparation session at home where they were coached on techniques to use when experiencing anxiety (CBT). This was followed by four VRE exposure sessions. For each participant the VRE scene was individualized based on their phobia).

A combination of CBT and gradual exposure in VR environments (Blue Room) were provided during the intervention. Each child had one assessment and preparation session at home where they were coached on techniques to use when experiencing anxiety (CBT). This was followed by a VRE exposure sessions. For each participant the VRE scene was individualized based on their phobia).
VRE scene prior to the phobia treatment.

Systematic desensitization/ extinction through graded exposure of Phobia.

Other Component: Session debriefing with the therapist and family to discuss planning for real life exposure to their phobia.
24 in. with an attached soundbar with stereo speakers.

iPad for therapist use to operate the graded exposure on the computer-generated scene.

\section{Antecedent Component:} Presession coaching was provided by a therapist for relaxation techniques in a relaxing VRE scene prior to the phobia treatment.

Systematic desensitization/ extinction through graded exposure of Phobia.

Other Component: Session debriefing with the therapist and family to discuss planning for real life exposure to their phobia.

\section{Semi-immersive \\ VR: Immersive technology} 'Blue Room', an advanced computer generated VRE. The Blue Room uses audiovisual images projected onto the walls and ceilings of a 360-degree seamless screened room.

iPad for therapist use to operate the graded exposure on the computer-generated scene.

\section{(1) Anxiety measured} via the Beck Anxiety Inventory and the Generalized Anxiety Disorder-7, (2) Depression measured via the Patient Health Questionnaire-9, (3) quality of life measured via the WHOQOLBREF, and (4) confidence measured via 6-point scale (feelings thermometer).
Intervention involved a combination of CBT and gradual exposure in virtual reality environments (Blue Room). Each participant had one assessment and $\mathrm{A}$ combination of CBT and gradual exposure in VR environments (Blue Room) were provided during the intervention. Each child had one assessment and preparation session at home where they were coached on

\section{Antecedent Component:} Presession coaching was provided by a therapist for relaxation techniques in a relaxing VRE scene prior to the phobia treatment.

Systematic desensitization/ extinction through graded exposure of Phobia.

Other Component: After the fourth sessions debriefing with the therapist, participant, and supporter was provided to discuss planning for real life exposure to their phobia.

\section{Semi-immersive}

VR: Immersive technology 'Blue Room', an advanced computer generated VRE. The Blue Room uses audiovisual images projected onto the walls and ceilings of a 360-degree seamless screened room.

iPad for therapist use to operate the graded exposure on the computer-generated scene. 
techniques to use when experiencing anxiety (CBT). This was followed by a VRE exposure sessions. For each participant the VRE scene was individualized based on their phobia.
McMahon (1) Total amount of st al. (2020) time participants engaged in exercise, (2) heart rate, and (3) calories burned.
Participants use a VR exercise game Virzoom where participants pedal a Stationary bike which corresponds to various games and scenarios in immersive VR.

\section{Antecedent}

Component: Adult delivery of equipment instruction prior to VR.

\section{Other}

Component: Embedded reinforcement (presence of VR game) for interacting with exercise.

\section{VR-based blood} draw to provide exposure therapy. As the participant viewed the blood draw simulation, a therapist attempted to replicate the sensations in real time that should accompany the video.

\section{Antecedent \\ Component: Prior to the start of the session the therapist determined the target step in which the participant would earn reinforcement and informed the participant of the contingency. While viewing the video, the therapist counted to help the participant predict when he could move his arm and gain reinforcement.}

\section{Consequence}

Component: The training involved a differential reinforcement of other behaviors procedure, in which, the participant was reinforced if no avoidance behavior occurred during a session. Edible reinforcement was provided by the therapist.

Miller et

al. (2020)

\section{(1) Activity}

completion measured

using a checkpoint completed during intervention assessing if the child attended to the duration of the VR checkpoint stimulation, (2) Travel ability measured using an air travel questionnaire.
VR-based air travel training module combined with traditional functional communication training based on an air travel experience. Individualized scripts for each child were delivered based on social stories. The final session was a realworld rehearsal.

\section{Antecedent}

Component: Prior to the start of the session a 15minute warm up activity was provided to help the child acclimate to the clinic. During the video a narrative script was provided to help the child attend to the VR simulation.

\section{Consequence}

Component: Reinforcement for functional communication responses
Fully Immersive VR: The VR exercise gaming platform used was the Virzoom exercise bike and the HTC VIVE VR goggles.

Apple Smartwatch (Version 2 ), was used to measure the heart rate and the duration of the exercise.

Fully Immersive VR: Virtual reality (VR) equipment consisted of a Tzumi Dream Vision VR Headset, an iPhone $6 s$ to display the VR video, and an Insta360 One VR camera. A 360-degree video of a blood draw was developed using the Insta 360 One VR camera equipped with two lenses that simultaneously record two 180-degree video images which combined to produce one 360-degree video.
Fully Immersive VR: VRbased air travel training module delivered on an iPhone X with a Google Cardboard device. 
and prompting of

replacement behaviors

delivered by therapist.

Simões et (1) Action accuracy

эl. (2018) measured via the number of correct actions for the task, (2) Debriefing accuracy measured via the accuracy of the participants describing the process of riding the bus, (3) Task duration in minutes for each session, and (4) Anxiety level measured via electrodermal activity (EDA) variation during each session.

Smith et al. (2014)

(1) Job interview skills rated on nine communication skills, and (2) Job interview self-confidence measure on sevenpoint Likert scale to answer 9 questions.
Participants were given a brief tutorial of game controls, then a task ranging in difficulty and complexity (taking one bus or two buses) for selecting a bus route and engaging in corresponding steps to reach the destination. At the end of every session the participant was asked to describe the process of riding a bus to the experimenter, but feedback was not provided. Intervention involved virtual reality job interview training which used strategies to target both job-relevant interview content and interviewee performance.
Antecedent

Component: Tutorial on game controls.

\section{Consequence}

Components: Feedback was provided by the VR system at the end of each task (scoring system evaluated the performance of the player on 2 different components: "Actions" and "Route"). A biofeedback system was implemented to adjust the environmental noises if needed.

\section{Antecedent}

Component: User informed of instructional strategies regarding job interview process prior to virtual interview via coursework. Prompts delivered to user via use of a help button within the VR job interview system.

\section{Consequence}

Component: Corrective feedback utilized displaying scores on key dimensions of performance allowing review of audio and written transcripts color coded for 'strong,' 'neutral,' or 'needs improvement' interview responses.

\section{Antecedent \\ Component: User informed of instructional strategies regarding job interview process prior to virtual interview via elearning coursework.}

Consequence Component: The VR system provided non-verbal cues and delivered prompts for relevant information, reinforcement (token economy), and corrective feedback.
Semi-immersive VR: The VR system was ran on a laptop computer (Windows 8.1, 16.0 GB RAM and an IntelCore i7 $2.50 \mathrm{GHz}$ processor). The head-mounted display used was Oculus Rift Development Kit 2, firmware version 2.12, and a gamepad was used for input.

A bracelet for wireless EDA recording (Biopac

Bionomadix BN-PPGED and MP150 amplifier).

\section{Non-immersive}

VR: Computer-based VR job interview training (VR-JIT) is a computerized virtual reality training simulation that can be used as computer software or via the internet. SIMmersion's patented PeopleSIMTM technology is the main platform for the simulated interactions in VRJIT.

\author{
Non-immersive \\ VR: Computer-based VR via \\ VIT-TAY software developed \\ by SIMmersion LLC.
}


interview skills

measured via the

Mock Interview

Rating Scale, (4) Self-

efficacy measured

via self-reported

scale, (5) Job

interview anxiety

measured via a

modified version of

the brief Personal

Report of Public

Speaking

Apprehension, and

(6) Vocational

outcomes
Smith et

al.

(2021b)
(1) Implementation outcomes measured via VR-JIT orientation acceptability, appropriateness, and expected implementation feasibility, (2) Effectiveness outcomes measured via vocational outcomes (employment)
Self-guided elearning materials and computer simulated job interview using virtual interviewers.

Antecedent

Component: User informed of instructional strategies regarding job interview process prior to virtual interview via elearning coursework.

\section{Consequence}

Component: The VR

system provided non-verbal cues and delivered prompts for relevant information, reinforcement, and corrective feedback.

Other Component: The system provides review of audio and written transcripts (color coded for 'strong,' 'neutral,' or 'needs improvement') interview responses.

Token reward system

Strickland Interview skills

et al.

(2013) measured via the

Interview Skills Rating Instrument

\section{Self-guided e- learning materials and computer simulated job interview using virtual interviewers.}

Written instructions were issued to each participant (treatment group) directing them to review all seven website subsections and the participants would complete two simulated job interviews.

\section{Antecedent}

Component: Systematic

instruction delivered via

multimedia employment

training

website. Embedded within

most subsections were

printable summaries,

graphic organizers,

worksheets, and

visual reminder cues.

\section{Consequence}

Component: Participants

received direct, positive feedback for areas of strength in practice interview and corrective feedback on areas of need via VR avatar assumed by the clinician.

\section{Non-immersive}

VR: Computer-based VR via VIT-TAY software developed by SIMmersion LLC.
Non-immersive VR: Computer based VR using websitebased Venugen platform (http://www.venuegen.com/). 
Wade et

al. (2016)

Driving performance

measured via median

trial duration to

assess task difficulty

and proficiency in

task completion and

median number of

trial failures per task

(e.g., adherence to

traffic laws, turning,

merging, speed

maintenance) pre-

and posttests.
Using the VR

driving module,

participants

completed a

practice driving

sessions for

assigned driving

tasks.
Antecedent Component: VR

equipment and program

pretraining by researcher.

Consequences

Component: Corrective

feedback via VR in the

form of object-highlighting

and audio/text

presentation. Positive

reinforcement (token

economy) was also

provided contingent upon a

successfully completed trial.
Semi-immersive VR: The VDM consists of both VR driving simulation software and a hardware driving interface that allow users to perform driving tasks in a controlled environment. A 3D model city was created via CityEngine and Autodesk Maya software, along with the Unity3D game to implement the VR driving application.

The Tobii X120 remote eyetracking device (www.tobii.com) was used to extract eye gaze data from participants.

Non-immersive VR: VR training programs and virtual tests were displayed on a 15inch Acer TravelMate 8204 laptop computer. Motioncapture technology was incorporated using a tracking webcam (Logitech QuickCam Pro 9000) to capture and project the child's image and movements into the virtual environment.

All software programs were programmed using Flash 8 with the programming language Actionscript 2.0. The programs were run using Macromedia Flash Player.
Ward \&

Esposito

(2018)
(1) Self-efficacy

measured via the General Self Efficacy

Scale, (2) Selfconfidence measured via the Interview Self Confidence Survey,

(3) Progress Monitoring within VRJIT, and (4) Student satisfaction.
The VR training program provided one class of object characteristics: perceptual, spatial, goal of each lesson was to teach the child to flexibly attend to object dimensions of that class.

The VR program presented each set of 10 training items in a predictable sequence. Motioncapture VR technology allowed for the child to see themselves on the screen and indicate responses through gestures (grab and dragging objects across the screen).

Virtual job interview training program (Job Interview Training with Molly Porter) that includes user-driven elearning, an interactive job application, and practice interview simulation with a virtual interviewer.

\section{Consequence}

Component: Researcher

elivered reinforcement.

built into the VR program

(correct responses

rewarded with a happy

face, while incorrect

responses were

discouraged with a sad face).
Antecedent Component: VR equipment and program pretraining by researcher using direct instruction in group setting.

\section{Consequence}

Component: Feedback delivered via VR to reinforce appropriate demonstration of job interviewing skills.
Non-immersive VR: VR-JIT system (developed by SIMmersion LLC) is a computerized job interview simulator delivered via the internet.

VR-JIT delivered with individual Google Chrome books equipped with headsets with microphones. 
Table 2

Quality Indicator Ratings for Group Experimental and Quasi-experimental Research

\begin{tabular}{|c|c|c|c|c|c|c|c|c|c|}
\hline & $\begin{array}{c}\text { Bozgeyikil } \\
\text { et al. } \\
\text { (2017) }\end{array}$ & $\begin{array}{l}\text { Burke } \\
\text { et al. } \\
\text { (2018) }\end{array}$ & $\begin{array}{l}\text { Burke } \\
\text { et al. } \\
\text { (2021) }\end{array}$ & $\begin{array}{c}\text { Cox et } \\
\text { al. } \\
(2017) \\
\end{array}$ & $\begin{array}{l}\text { Genova } \\
\text { et al. } \\
(2012)\end{array}$ & $\begin{array}{l}\text { Humm } \\
\text { et al. } \\
\text { (2014) }\end{array}$ & $\begin{array}{l}\text { Maskey } \\
\text { et al. } \\
(2014)\end{array}$ & $\begin{array}{l}\text { Maskey } \\
\text { et al. } \\
\text { (2019a) }\end{array}$ & $\begin{array}{l}\text { Maskey } \\
\text { et al. } \\
\text { (2019b) }\end{array}$ \\
\hline \multirow{2}{*}{\multicolumn{10}{|c|}{$\begin{array}{l}\text { Primary } \\
\text { Indicators }\end{array}$}} \\
\hline & & & & & & & & & \\
\hline $\begin{array}{c}\text { Participant } \\
\text { information }\end{array}$ & $\mathrm{U}$ & A & A & $\mathrm{H}$ & $\mathrm{U}$ & A & $\mathrm{H}$ & $\mathrm{H}$ & $\mathrm{H}$ \\
\hline $\begin{array}{r}\text { Independent } \\
\text { variable }\end{array}$ & $\mathrm{H}$ & $\mathrm{H}$ & $\mathrm{H}$ & $\mathrm{H}$ & $\mathrm{H}$ & $\mathrm{H}$ & A & $\mathrm{H}$ & $\mathrm{H}$ \\
\hline $\begin{array}{r}\text { Control } \\
\text { condition }\end{array}$ & $\mathrm{H}$ & $\mathrm{U}$ & $\mathrm{U}$ & $\mathrm{H}$ & $\mathrm{H}$ & $\mathrm{H}$ & $\mathrm{U}$ & $\mathrm{U}$ & $\mathrm{H}$ \\
\hline $\begin{array}{l}\text { Dependent } \\
\text { variable }\end{array}$ & U & $\mathrm{H}$ & $\mathrm{H}$ & $\mathrm{H}$ & $\mathrm{H}$ & $\mathrm{H}$ & $\mathrm{U}$ & $\mathrm{U}$ & U \\
\hline $\begin{array}{r}\text { Link Between } \\
\text { Research } \\
\text { Question and } \\
\text { Data Analysis }\end{array}$ & A & $\mathrm{H}$ & $\mathrm{H}$ & $\mathrm{H}$ & $\mathrm{H}$ & $\mathrm{H}$ & $\mathrm{H}$ & $\mathrm{H}$ & $\mathrm{H}$ \\
\hline $\begin{array}{r}\text { Use of } \\
\text { Statistical Tests }\end{array}$ & $\mathrm{H}$ & $\mathrm{H}$ & $\mathrm{H}$ & $\mathrm{H}$ & $\mathrm{H}$ & $\mathrm{H}$ & $\mathrm{U}$ & $\mathrm{U}$ & $\mathrm{H}$ \\
\hline \multicolumn{10}{|l|}{$\begin{array}{l}\text { Secondary } \\
\text { Indicators }\end{array}$} \\
\hline $\begin{array}{r}\text { Random } \\
\text { assignment }\end{array}$ & 0 & 0 & 0 & 0 & 1 & 1 & 0 & 0 & 1 \\
\hline $\begin{array}{r}\text { Interobserver } \\
\text { agreement }\end{array}$ & 1 & 0 & 0 & 1 & 1 & 1 & 1 & 1 & 1 \\
\hline Blind raters & 1 & 1 & 0 & 1 & 1 & 0 & 1 & 1 & 1 \\
\hline Fidelity & 0 & 1 & 0 & 0 & 1 & 1 & 0 & 0 & 0 \\
\hline Attrition & 1 & 1 & 1 & 0 & 1 & 0 & 1 & 1 & 1 \\
\hline $\begin{array}{l}\text { Generalization } \\
\text { or maintenance }\end{array}$ & 0 & 0 & 0 & 0 & 0 & 0 & 1 & 0 & 1 \\
\hline Effect size & 1 & 1 & 1 & 1 & 1 & 1 & 0 & 0 & 1 \\
\hline Social validity & 1 & 1 & 1 & 1 & 1 & 1 & 0 & 0 & 1 \\
\hline
\end{tabular}

1 Codes for quality ratings for primary indicators are as follows: $\mathrm{H}=$ high quality, $\mathrm{A}=$ acceptable, and $\mathrm{U}=$ unacceptable

2 Codes for quality ratings for secondary indicators are as follows: $1=$ criteria met, $0=$ criteria not me

Table 2 (cont.)

Quality Indicator Ratings for Group Experimental and Quasi-experimental Research 


\begin{tabular}{|c|c|c|c|c|c|c|c|c|c|}
\hline & $\begin{array}{c}\text { Maskey } \\
\text { et al. } \\
(2019 c) \\
\end{array}$ & $\begin{array}{c}\text { Miller } \\
\text { et al. } \\
(2020)\end{array}$ & $\begin{array}{c}\text { Simões } \\
\text { et al. } \\
(2017) \\
\end{array}$ & $\begin{array}{l}\text { Smith } \\
\text { et al. } \\
(2014)\end{array}$ & $\begin{array}{c}\text { Smith } \\
\text { et al. } \\
(2021 \mathrm{a}) \\
\end{array}$ & $\begin{array}{c}\text { Smith } \\
\text { et al. } \\
(2021 \mathrm{~b}) \\
\end{array}$ & $\begin{array}{c}\text { Strickland } \\
\text { et al. } \\
(2013) \\
\end{array}$ & $\begin{array}{l}\text { Wade } \\
\text { et al. } \\
(2016)\end{array}$ & $\begin{array}{c}\text { Ward \& } \\
\text { Esposito } \\
(2018) \\
\end{array}$ \\
\hline \multicolumn{10}{|l|}{ Primary } \\
\hline Indicators & & & & & & & & & \\
\hline $\begin{array}{l}\text { Participant } \\
\text { information }\end{array}$ & $\mathrm{H}$ & A & $\mathrm{H}$ & A & $\mathrm{H}$ & A & $\mathrm{U}$ & $\mathrm{H}$ & $\mathrm{H}$ \\
\hline $\begin{array}{r}\text { Independent } \\
\text { variable }\end{array}$ & $\mathrm{H}$ & $\mathrm{U}$ & $\mathrm{A}$ & $\mathrm{H}$ & $\mathrm{H}$ & $\mathrm{H}$ & $\mathrm{H}$ & $\mathrm{H}$ & $\mathrm{H}$ \\
\hline $\begin{array}{r}\text { Control } \\
\text { condition }\end{array}$ & $\mathrm{U}$ & $\mathrm{U}$ & $\mathrm{H}$ & $\mathrm{H}$ & $\mathrm{H}$ & $\mathrm{H}$ & A & $\mathrm{H}$ & $\mathrm{U}$ \\
\hline $\begin{array}{l}\text { Dependent } \\
\text { variable }\end{array}$ & $\mathrm{U}$ & $\mathrm{U}$ & $\mathrm{H}$ & $\mathrm{H}$ & $\mathrm{H}$ & $\mathrm{H}$ & $\mathrm{H}$ & $\mathrm{H}$ & $\mathrm{H}$ \\
\hline $\begin{array}{r}\text { Link Between } \\
\text { Research } \\
\text { Question and } \\
\text { Data Analysis }\end{array}$ & $\mathrm{H}$ & A & A & $\mathrm{H}$ & $\mathrm{H}$ & $\mathrm{H}$ & $\mathrm{H}$ & $\mathrm{H}$ & $\mathrm{H}$ \\
\hline $\begin{array}{r}\text { Use of } \\
\text { Statistical } \\
\text { Tests }\end{array}$ & $\mathrm{H}$ & $\mathrm{U}$ & A & $\mathrm{H}$ & $\mathrm{H}$ & $\mathrm{H}$ & $\mathrm{H}$ & $\mathrm{H}$ & $\mathrm{H}$ \\
\hline \multicolumn{10}{|l|}{$\begin{array}{l}\text { Secondary } \\
\text { Indicators }\end{array}$} \\
\hline $\begin{array}{r}\text { Random } \\
\text { assignment }\end{array}$ & 0 & 0 & 0 & 1 & 0 & 1 & 1 & 1 & 0 \\
\hline $\begin{array}{r}\text { Interobserver } \\
\text { agreement }\end{array}$ & 1 & 0 & 0 & 1 & 0 & 1 & 1 & 0 & 1 \\
\hline Blind raters & 1 & 0 & 0 & 1 & 0 & 0 & 1 & 0 & 1 \\
\hline Fidelity & 0 & 0 & 1 & 0 & 1 & 1 & 0 & 1 & 1 \\
\hline Attrition & 1 & 1 & 1 & 1 & 0 & 1 & 1 & 1 & 1 \\
\hline $\begin{array}{r}\text { Generalization } \\
\text { or } \\
\text { maintenance }\end{array}$ & 1 & 1 & 0 & 0 & 1 & 1 & 0 & 0 & 0 \\
\hline Effect size & 0 & 0 & 1 & 1 & 0 & 0 & 1 & 1 & 1 \\
\hline Social validity & 0 & 1 & 1 & 1 & 1 & 1 & 1 & 0 & 1 \\
\hline
\end{tabular}

1 Codes for quality ratings for primary indicators are as follows: $\mathrm{H}=$ high quality, $\mathrm{A}=$ acceptable, and $\mathrm{U}=$ unacceptable

2 Codes for quality ratings for secondary indicators are as follows: $1=$ criteria met, $0=$ criteria not me

\section{Table 3}

Quality Indicator Ratings for Single-case Research 


\begin{tabular}{|c|c|c|c|c|c|c|}
\hline & $\begin{array}{l}\text { Dixon et } \\
\text { al. (2017) }\end{array}$ & $\begin{array}{l}\text { Hu \& Han et } \\
\text { al. (Year) }\end{array}$ & $\begin{array}{l}\text { Johnston et } \\
\text { al. (2020) }\end{array}$ & $\begin{array}{l}\text { McMahon et } \\
\text { al. (2020) }\end{array}$ & $\begin{array}{l}\text { Meindl et } \\
\text { al. (2019) }\end{array}$ & $\begin{array}{c}\text { Wang \& } \\
\text { Reid (2013) }\end{array}$ \\
\hline \multicolumn{7}{|l|}{ Primary } \\
\hline \multicolumn{7}{|l|}{ Indicators } \\
\hline $\begin{array}{r}\text { Participant } \\
\text { information }\end{array}$ & A & $\mathrm{H}$ & $\mathrm{A}$ & $\mathrm{U}$ & $\mathrm{A}$ & $\mathrm{H}$ \\
\hline $\begin{array}{r}\text { Independent } \\
\text { variable }\end{array}$ & $\mathrm{H}$ & $\mathrm{H}$ & $\mathrm{H}$ & $\mathrm{H}$ & $\mathrm{H}$ & $\mathrm{H}$ \\
\hline $\begin{array}{r}\text { Dependent } \\
\text { variable }\end{array}$ & $\mathrm{H}$ & $\mathrm{H}$ & A & $\mathrm{H}$ & $\mathrm{H}$ & A \\
\hline Baseline & $\mathrm{A}$ & $\mathrm{H}$ & $\mathrm{U}$ & $\mathrm{H}$ & $\mathrm{H}$ & A \\
\hline Visual analysis & $\mathrm{H}$ & $\mathrm{H}$ & $\mathrm{U}$ & $\mathrm{H}$ & $\mathrm{A}$ & $\mathrm{A}$ \\
\hline $\begin{array}{r}\text { Experimental } \\
\text { control }\end{array}$ & $\mathrm{H}$ & $\mathrm{H}$ & $\mathrm{H}$ & $\mathrm{H}$ & $\mathrm{H}$ & $\mathrm{H}$ \\
\hline \multicolumn{7}{|l|}{$\begin{array}{l}\text { Secondary } \\
\text { Indicators }\end{array}$} \\
\hline $\begin{array}{r}\text { Interobserver } \\
\text { agreement }\end{array}$ & 1 & 1 & 0 & 1 & 1 & 1 \\
\hline Карра & 0 & 0 & 0 & 0 & 0 & 1 \\
\hline Blind raters & 0 & 0 & 1 & 0 & 0 & 1 \\
\hline Fidelity & 0 & 0 & 0 & 1 & 1 & 1 \\
\hline $\begin{array}{r}\text { Generalization or } \\
\text { maintenance }\end{array}$ & 1 & 1 & 0 & 0 & 1 & 0 \\
\hline Social validity & 1 & 1 & 0 & 1 & 1 & 0 \\
\hline
\end{tabular}

1 Codes for quality ratings for primary indicators are as follows: $\mathrm{H}=$ high quality, $\mathrm{A}=$ acceptable, and $\mathrm{U}=$ unacceptable

2 Codes for quality ratings for secondary indicators are as follows: $1=$ criteria met, $0=$ criteria not met 